\title{
Cyclobutadienes via an Organocascade
}

\section{Key words}

cyclobutadienes

ynals

$\alpha, \beta$-unsaturated aldehydes

[2+2] cycloaddition<smiles>O=CC#CC=O</smiles>

catalyst $(20 \mathrm{~mol} \%)$

$\mathrm{K}_{2} \mathrm{CO}_{3}(20 \mathrm{~mol} \%)$

PhMe
r.t., $72 \mathrm{~h}$

$\mathrm{R}=\mathrm{Ar}, c-\mathrm{Pr}, \mathrm{MeBn}, \mathrm{SiMe}_{2} \mathrm{Ph}$

Selected examples:<smiles>O=CC1=C(c2ccccc2)C(/C=C/c2ccccc2)=C1</smiles>

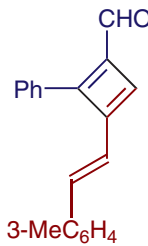

$84 \%$ yield
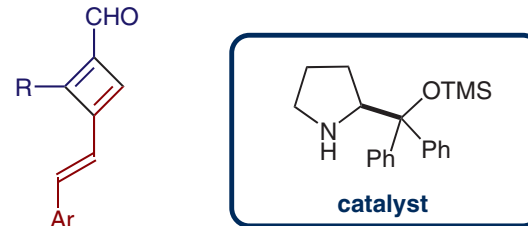

18 examples $78-93 \%$ yield

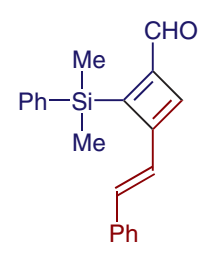

$78 \%$ yield

Proposed mechansim:

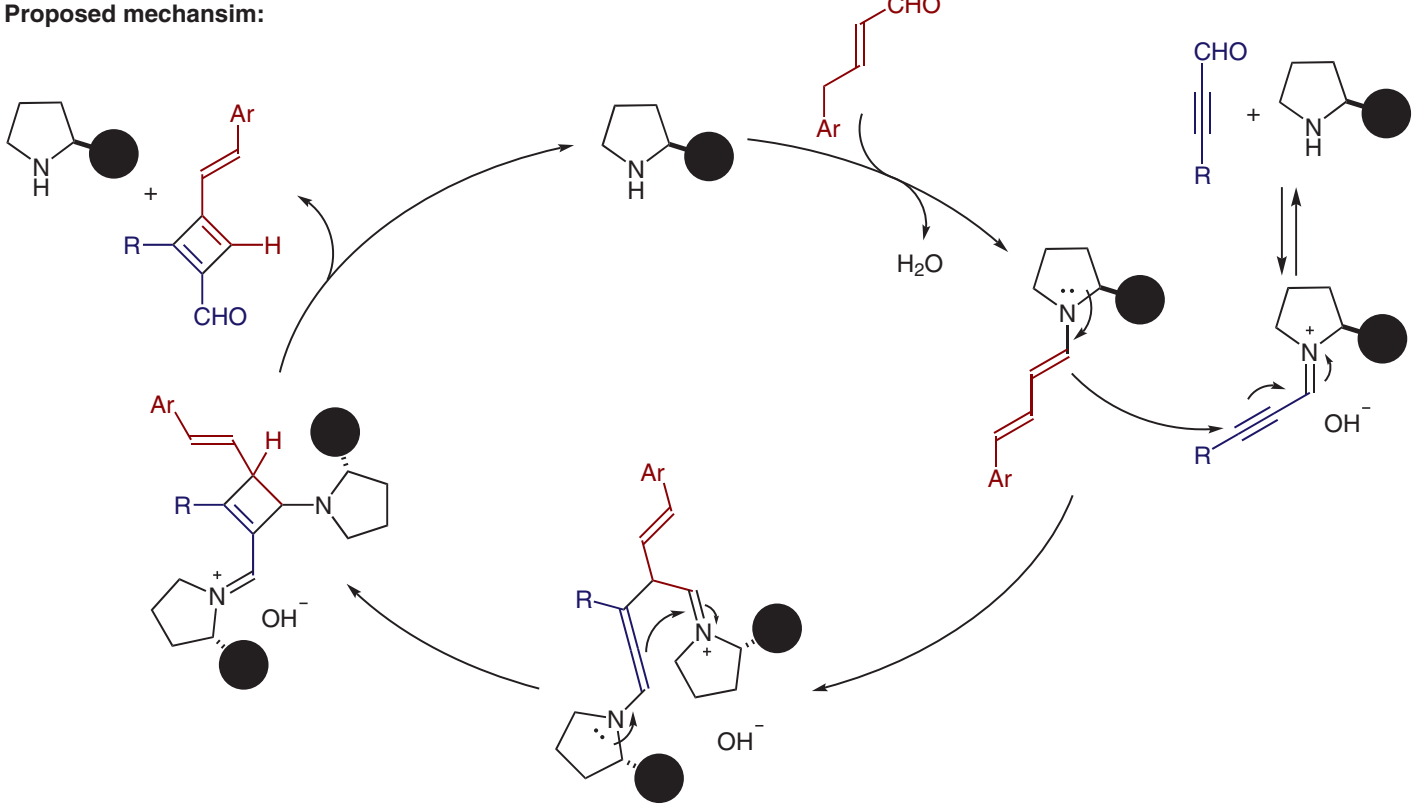

Significance: The Wang group reports an organocatalytic [2+2] cycloaddition between $\alpha, \beta$-unsaturated aldehydes and ynals. This reaction is catalyzed by secondary amines and generates cyclobutadienes in high yields under mild conditions.
Comment: The authors suggest that the reaction follows a dienamine-iminium-allenamine cascade sequence furnishing cyclobutadienes as products. Typically high temperatures are required for the synthesis of cyclobutadienes. This method requires only room temperature, hence overcoming a limitation of previous methods. 